\title{
Presidential address (ISPN 2015, Izmir)
}

\author{
Chandrashekhar E. Deopujari ${ }^{1}$
}

Received: 3 June 2016 / Accepted: 16 June 2016

(C) Springer-Verlag Berlin Heidelberg 2016

\section{Izmir/Smyrna: the history of ancient civilizations}

Izmir, the venue of this conference, was known as Smyrna in ancient times. As a result of excavations carried out on the Yesilova mound located in the subdistrict of Bornova, on the eastern side of the Bay of Izmir, it has now become clear that Izmir's past goes back 8500 years. This probably was the first evidence of civilization anywhere in this world. Another evidence of the fact that this area was "the cradle of civilization" was found some years ago in the nearby Anatolia region, namely Gobekeli Tepe, which is now immersed in the Ataturk Dam [1].

Close to this region, and much less visited, was Nevali Cori. This spot of lost civilization was excavated by the archeology team of Professor Herald Hauptmann of Heidelberg. The adjoining areas are rich in Neolithic (New Stone Age) settlements dating back to about 6000 B.C.; but the Nevali Cori site dates back to beyond 7000 B.C. It is a great tragedy that the oldest known civilization had, by mid-1992, been all but submerged under the waters of the Ataturk Dam. Many of the excavated materials and objects have been transported to the Archaeological Museum at Urfa.

Probably the most impressive sculpture found from Nevali Cori is that of a skin-headed God and has puzzled the archeologists as it is identical to the head of a Vedic priest, common in India even today. According to this archeological evidence, one of the oldest known sculptures in the world may have origins in the Vedic times of ancient Indian culture.

Chandrashekhar E. Deopujari

d.chandrashekhar11@gmail.com

1 Department of Neurosurgery, Bombay Hospital Institute of Medical Sciences, 126-B, MRC, Bombay Hospital, 19 New Marine Lines, Mumbai 400020, India
There are also some influences around 2000 B.C., of IndoAryan culture in the Anatolia region and many similarities with the Sumerian tradition of about 3000 B.C., viz. the typical luni-solar calendar or the practice of addition of extra months to the year. Although, the civilization of the Indus valley was found much later, the stone built cylindrical walls are similar in architecture to the Anatolian excavations. Similar structures in the form of a study (meditation centers) have been found in Nalanda, India, which is the oldest known university complex in the world [1].

The Indus civilization flourished from 2500 to 1500 B.C. centered in the northwest of India, around Mohenjo-Daro and Harappa. An astonishing feature of this pre-Aryan urban culture was its advanced system of public sanitation. There were numerous wells, bathrooms, public baths, sewers, and chutes for collecting trash. Streets were laid out in regular fashion, and houses were well built and ventilated. Sir John Marshall tells us that civilization created at these two places is not incipient but one already age old with millennium of human endeavor on Indian soil behind it [2]. Thus, India must be recognized, along with Persia, Mesopotamia, and Egypt as one of the most important areas where the civilizing processes were initiated and developed. All the evidence thus suggests that there may have been a great connection between the ancient civilizations of both Turkey and India.

\section{Indian civilization through ages}

The early education system in India followed an oral tradition, with hardly any knowledge written in any permanent form. This makes understanding the traditions difficult. The ancient Indians made themselves known exclusively through their language and their cult. "Words and Gods. They left nothing else. Nor wished to perhaps. They built no stone temples, no 
palaces. They left no chronicles of their achievements, made no lists of their possessions, created no images that survived the course of time." This sentence from the book Ka by Roberto Calasso [3] is telling indeed. Perhaps they felt such things as knowledge, was passed on as it would be heard through the teachers (gurus) to their students (shishyas). Thus was established what is known as the guru-shishya parampara. This mentor-student relationship exists even today in the Indian education system, more evident in surgical specialties.

First Prime Minister of India, Pandit Jawaharlal Nehru was particularly struck by the love of learning of the Indian people and wrote a book, "The Discovery of India" during his freedom struggle imprisonment, elucidating early Indian history. Among the most ancient printed books discovered in China are books in Sanskrit (the ancient Indian language) from the eighth century A.D. These were printed from wooden blocks as per the printing technology developed in China at the time. In the tenth century, the Imperial Printing Commission was organized in China and as a result of this, and right up to the Sung era, the art of printing developed rapidly. It is surprising and difficult to account for that, in spite of the close contacts between Indian and Chinese scholars, there is no evidence whatsoever of the printing of books in India during that period.

One of the Chinese scholars, who studied at the Nalanda University, Hsuan-Tsang's book the Si-Yu-Ki or the Record of the Western Kingdom (meaning India) makes fascinating reading. Coming from a highly civilized and sophisticated country, at a time when China's capital Si-an-Fu was a predominant center of art and learning, his comments on and descriptions of conditions in India are valuable. He tells us of a system of education in India which began early and proceeded by stages to the university where the five branches of knowledge taught were the following: (1) grammar, (2) science of arts and crafts, (3) medicine, (4) logic, and (5) philosophy [4].

Before the beginning of the Christian era, six prominent Brahminical belief systems had taken shape and crystallized themselves, out of the welter of many such systems. Each one of them represents an independent approach, a separate argument, and yet they were not isolated from each other but rather parts of a larger plan. The six systems are known as (1) Nyaya, the school of logical reasoning; (2) Vaishesika, an atomist school dealing with the interplay of atoms within nature; (3) Samkhya, the school of enumeration; (4) Yoga, the school of Patanjali; (5) Mimumsa, the tradition of Vedic exegesis, with emphasis on Vedic ritual; and (6) Vedanta, the Upanishadic tradition, with emphasis on Vedic philosophy. Indian (Hindu) philosophy is distinctive in its application of analytical rigor to metaphysical problems and goes into very precise detail about the nature of reality, the structure and function of the human psyche, and how the relationship between the two has important implications for human salvation.

\section{Unity in diversity}

India today has more than two thousand ethnic groups and every major religion is represented in the country, as are the four major families of languages (Indo-European, Dravidian, Austroasiatic, and Sino-Tibetan). The modern Indian republic is home to $97 \%$ of Jains, $90 \%$ of Sikhs, $50 \%$ of Zoroastrians, $40 \%$ of Baha'i, $20 \%$ of Shia, $10 \%$ of Muslims, $5 \%$ of Ahmadiyya, $2 \%$ of Buddhists, and $1 \%$ of Christians worldwide. All these religions exist in a mostly peaceful cohabitation with the majority religion of the country which is Hinduism. Religious co-existence can be epitomized through the attitudes its spiritual leader, Swami Vivekananda, who once said, "I challenge the world to find, throughout the whole system of Sanskrit philosophy, any such expression as that the Hindu alone will be saved and not others."

In the Indian general elections of 2004 (as per the constitution written by a Buddhist, Dr. Ambedkar), we witnessed the phenomenon of an election being won by a woman political leader of Italian origin and Roman Catholic faith, Sonia Gandhi, who then made way for a Sikh, Dr. Manmohan Singh, to be sworn in as Prime Minister by a Muslim President, Dr. Abdul Kalam, in a country that is $81 \%$ Hindu in composition [5].

\section{India: the next twenty-first century power?}

India is the second most populated country in the world with 1.27 billion people. If the growth continues at this rate, it is poised to overtake China by 2034. In terms of military strength India has the world's fourth largest army and has nuclear capabilities. The Indian economy is now the fifth largest economy in the world in purchasing power parity terms. And it continues to grow. When the rest of the world took a beating in 2008, it grew at $6.7 \%$.

Of all the statistics, I believe the power lies in the fact that $65 \%$ of the Indian population is under the age of 35 years. The average age of the country is 28 years (China 38 , USA and EU 46, and Japan 47). India has 226 million students joining higher education and 160 million people starting their working life, as compared to 87 million in China.

India has made great progress in education and literacy. Climbing from a literacy rate of $16 \%$ in 1947 (year of independence) to $76 \%$ today. The statistics are even better when we consider that the coverage of primary education is now $100 \%$, and $95 \%$ of 12 year olds in the country can read and write. For a country of 1.27 billion, with a history of British rule and existing poverty, this is an excellent progress. As we know, better education is important not just for the economy but for national security and healthcare as well. The number of universities in India stands close to 700; up from merely 27 universities in 1947. 


\section{Education and scientific research in India}

The rapid progress in numbers may have come at the cost of the core quality of the education provided. A telling statistic is that $65 \%$ of employers are unhappy with the quality of their employees. Hence, education reform should definitely be high up on the government's agenda. The main imbalance can be seen when we consider the paucity of research output from India. We have $17 \%$ of the world's higher education acquired population and yet only $2.4 \%$ of research output [6].

One of the reasons for this is the many languages in India. The number of official languages is now at 21. English as a form of communication continues to gain popularity and most of us are educated in English, especially in medicine. However, there is a large rural population, containing many intelligent people, who are unable to grasp English and therefore, they lose out on higher technical education and the country loses out on the great potential they possess to contribute to the field of medicine.

In fact, the government set up six institutes between 2006 and 2008 to figure out why scientific research in India is lacking and how it can be improved. What was found, however, was that from the 600 students who graduated from these systems and secured $\mathrm{PhD}$ positions, $60 \%$ of these positions were in universities abroad. This is referred to as the "brain drain" or more recently referred as "India's brain reserve." This has gone to such an extent that the heads of Google, Microsoft, and PepsiCo are all IIT graduates from India. Estimates in 2000 have shown that India had become the \#1 exporter of healthcare professionals to the world.

This sort of brain drain is why the Indian system is seriously afflicted by a lack of post-doctoral fellows, who are the engine of all research enterprise. For every 100,000 Indians, we only have 54.27 doctors and 75.89 nurses. In comparison, the USA has 240 medical personnel per 100,000 citizens.

\section{Healthcare in India}

Ayurvedic medicine was based on a vast literature which included not only the Vedas and their later commentaries by the Brahmanas (Aranyakas and Upanishads) but also a body of medical writings by many contributors, of whom two stand out as the most influential: Charaka and Sushruta. Estimates have varied widely on their dates, as some have suggested the first century A.D. for Charaka and the fourth century for Sushruta, but there are also claims for more ancient times. The physicians included both surgery and medicine in their practice.

Sushruta wrote, "Only the union of medicine and surgery constitutes the complete doctor. The doctor who lacks knowledge of one of these branches is like a bird with only one wing $[7,8]$." According to Sir William Hunter, "The surgery of the ancient Indian physicians was bold and skillful. A special branch of surgery was dedicated to rhinoplasty or operations for improving deformed ears, noses and forming new ones, which European surgeons have borrowed".

There is a huge rural vs urban divide in the healthcare system in India. While the opportunity to enter the "market" is very ripe, India still spends only around $4.2 \%$ of its national GDP towards healthcare goods and services $(18 \%$ by the USA). The out of pocket expenditure for patients is very high at $70 \%$. Only $5 \%$ of Indians are covered by health insurance policies. There is a great need for effective payment mechanisms. For primary healthcare, the Indian government spends only about $30 \%$ of the country's total healthcare budget. There is a great demand for basic primary healthcare and infrastructure. Today, India is the third largest exporter of pharmaceutical products in terms of volume. Around $80 \%$ of the market is composed of generic low-cost drugs which seem to be the major driver of this industry. However, the medical devices sector is very underdeveloped. This is a great shame in a country that boasts of so many technical professionals who are proficient in computer sciences and engineering.

Though India has now become the fifth largest economy in the world, the large population in this country puts a huge strain on public spending. In income equality (Gini coefficient), India falls somewhere in the middle, in the 30-35 category, (if $0=$ income equality) though, it still harbors one third of the world's poor as per World Bank statistics. With a large amount of private sector spending, healthcare facilities have improved in India and quality of healthcare in many centers is on par with the best in the world. However, it still has the stigma of being the country with maximum road deaths and is labeled as the "head injury capital" of the world.

\section{Specialization in medicine}

Though specialization in medicine has a long history, its importance has been re-emphasized in a recent survey undertaken by Atul A. Gawande, MD, of Brigham and Women's Hospital in Boston [9]. The survey outlined strategies to improve outcomes for patients undergoing neurosurgical procedures. The researchers analyzed data and determined six factors contributing to neurosurgical adverse events: (1) surgical technique, (2) perioperative medical management, (3) nonadherence to protocol, (4) preoperative optimization, (5) technology, and (6) communication.

Based on an analysis of these factors, the researchers then detailed five ways healthcare providers can prevent neurosurgical adverse events. One of the main points was to improve subspecialization and regionalization in neurosurgery. Regionalization and subspecialization would help prevent adverse events that are unique to certain procedures and 


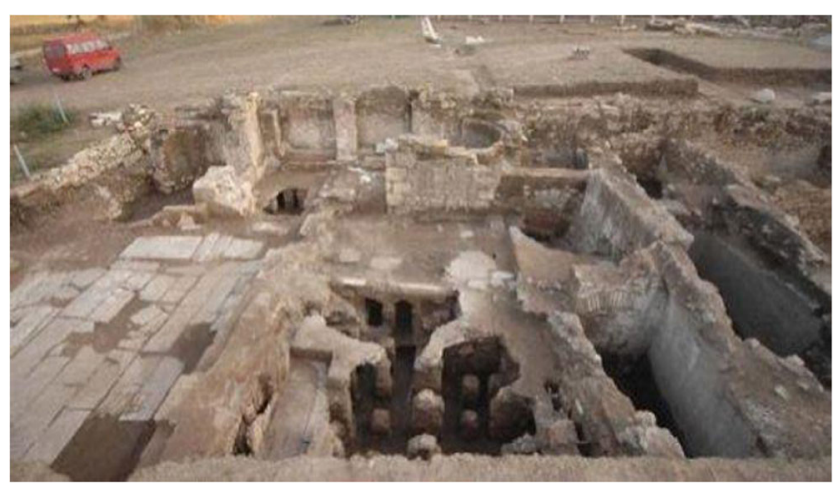

Fig. 1 Yesilova mound near Izmir

techniques. Development of Centers of Excellence in neurosurgery could boost these efforts. The other points encompassed establishing guidelines and protocols, standardizing equipment, adopting process and outcome monitoring and implementing the WHO Surgical Safety Checklist.

The survey emphasizes the need for specialization and subspecialization in neurosurgery. However, there are contrary views as well, considering the wisdom of specialization. The opponents of specialization point to the fact that the current categorization of neurosurgical subspecialties represents an incongruent group of "areas of interest" whose origins are historical in their development and whose boundaries are indistinct, artificial, and often fail to share a common theme [10].

According to the research conducted by Dr. Datta Muzumdar, a colleague neurosurgeon from Mumbai, the utility of specialization in India must be rethought [11]. A vast majority of Indians residing in rural areas have limited or no access to basic medical and surgical facilities. The major health needs of the country are control of malnutrition, acute respiratory infections, tuberculosis, HIV disease, diarrheal diseases, and other infectious diseases. In such a situation, the need to focus on advanced subspecialization could easily be questioned. The infrastructure needed for nurturing advanced subspecialization is mainly available in private rather than public sector hospitals. Few public hospitals have been able to generate advanced subspecialists in a comprehensive manner due to budgetary and human resource constraints. The advanced subspecialization services come at a premium and the long-term viability of such a program needs to be ascertained in terms of monetary recovery and increasing healthcare costs. Over a period of time, the comprehensive care provided by an advanced subspecialist will be certainly superior to those involved in the management of this disease along with other diseases. Barondess et al. have raised concern about the splintering effects of advanced subspecialization and its potential to increase the cost of healthcare delivery.

To ensure that their money's worth is properly accounted for, the insurance companies would indirectly enforce the defining roles of a subspecialist. It is possible that the hospitals would be more inclined to appoint an advanced subspecialist to deliver appropriate healthcare. If advanced subspecialty practice is here to stay, then it is better that the medical regulatory bodies at the local and national level should take the reins in their hands and focus on these areas.

\section{Pediatric neurosurgery in India}

Since 1973 till date, we have seen an effective decrease in the rates of infant mortality in India. However, at close to 50 deaths per 1000, this is still not acceptable as India also has the largest child population in the world. Despite this, the specialty of pediatric neurosurgery was not very well developed. This was likely due to the small number of neurosurgeons in the country in the first place. In the 1980s, however, the first course on pediatric neurosurgery was conducted by Raja Reddy and KVR Sastry in Hyderabad in 1985. The focus was on hydrocephalous and congenital malformations with A. Hockley, R. Kalbag as faculty.

This was followed in 1988 by Dr. S.N. Bhagwati in Mumbai with a symposium on Pediatric CNS infections. Dr. Bhagwati then acted as a catalyst by inviting the International Society of Pediatric Neurosurgery to hold their 17th annual meeting in Mumbai in 1989, when Dr. Fred Epstein was ISPN President. ISPN has played a great role in India for the development of pediatric neurosurgery.

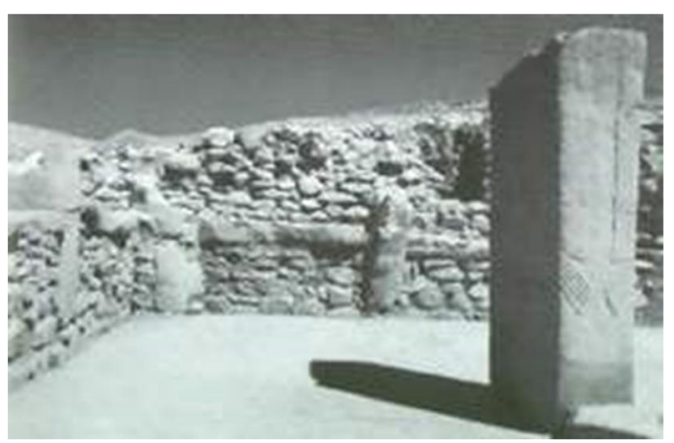

a

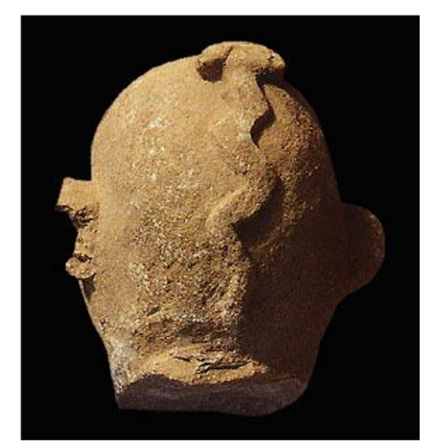

b

Fig. 2 a Nevali Cori structure in ancient Anatolia. b. Head with Shikha found at Nevali Cori 


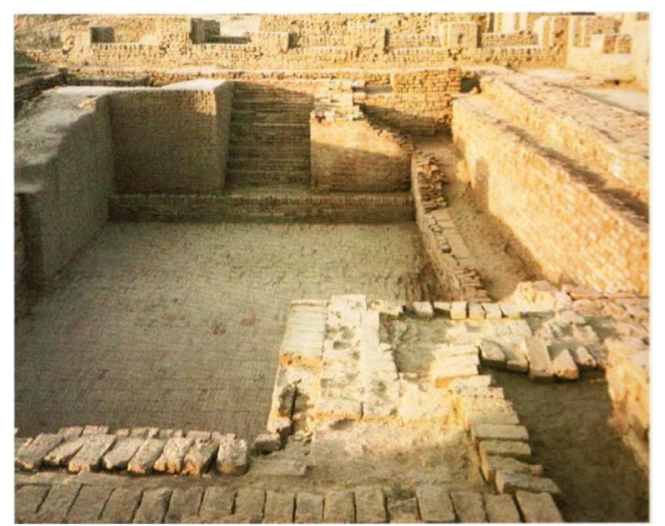

Fig. 3 Harappa structure showing well constructed drains and lanes

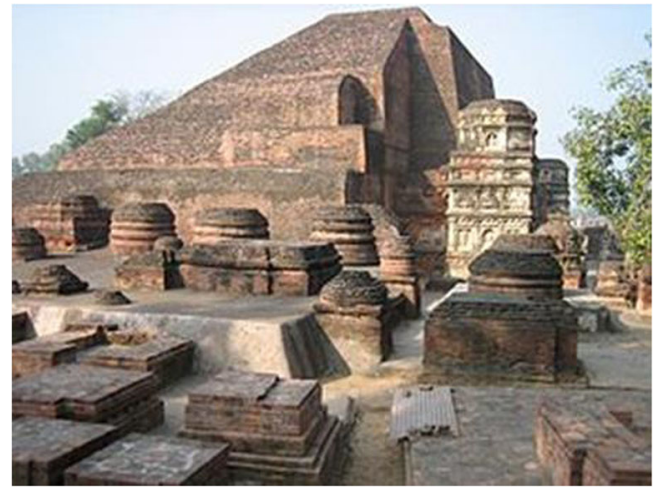

Fig. 4 Nalanda Mahavihar in Northern India

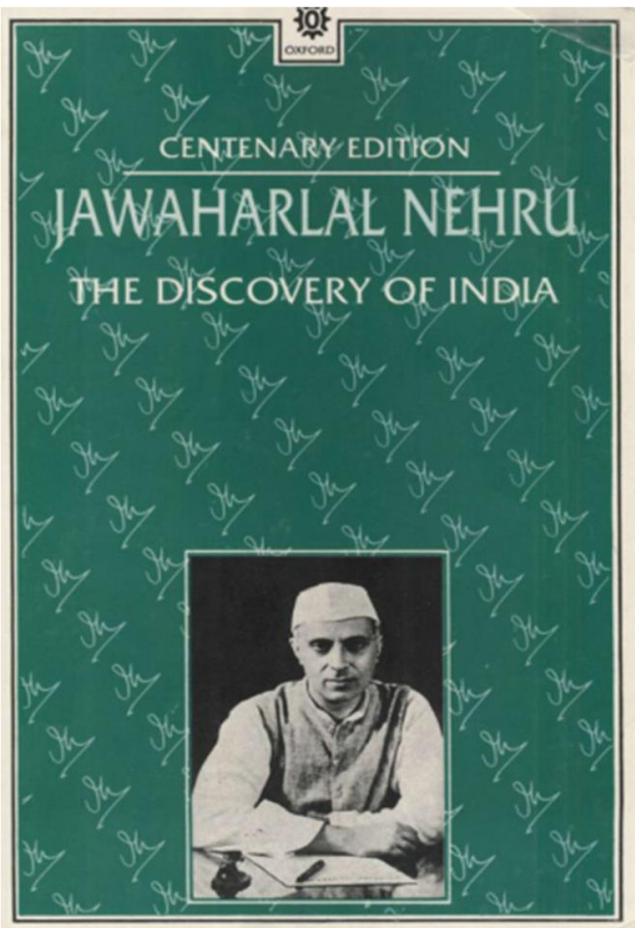

Fig. 5 Discovery of India: Jawaharlal Nehru (the book)
In 1991, the Indian Society of Pediatric Neurosurgery was formed. It has now 200 members, annual meetings, and educational courses, helped by the ISPN. The Pediatric Neurosurgery society became the first organized subspecialty in neurosurgery in India. Dr. Bhagwati's becoming ISPN President in 1995 was a big honor for the country. The most remarkable thing to have happened is the ISPN's association with the educational courses in India, which have been a very successful in the three cycles so far and the fourth cycle will begin soon. The ISPN meeting in Goa, India, in 2011 was also a great revitalizer for the pediatric community in India.

Today in India, there are over 15 major institutions which can be called centers of excellence, contributing to patient care as well as scientific publications. Several neurosurgeons are interested and are practicing pediatric neurosurgery, however, only a dozen of them practice exclusively Pediatric Neurosurgery. There is an opportunity here to treat a large number of patients well and contribute to science with collaborative projects within the country with the Indian diaspora and other international centers and organizations. In fact, it can become a model center for training neurosurgeons interested in pediatrics; not only for India but for many other less developed as well as better developed countries.

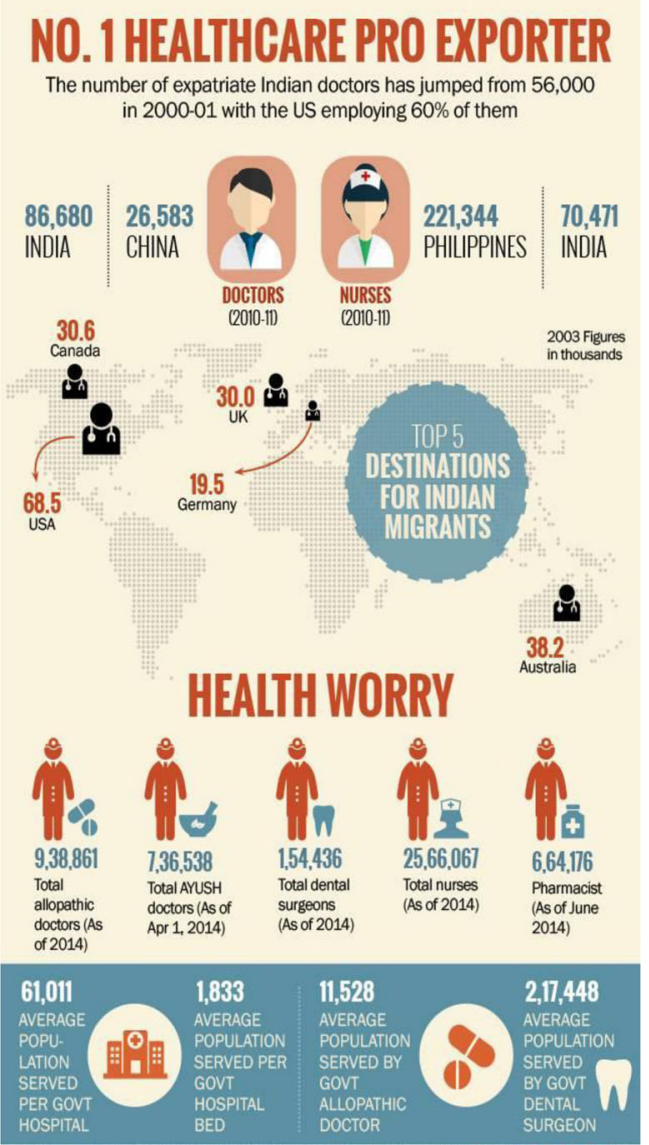

Fig. 6 India the No.1 Pro Health Exporter 
The mission of the ISPN is to promote the health of children throughout the world by encouraging the ethical transmission and exchange of neuroscientific information and techniques related to pediatric neurosurgery. I believe Indian neurosurgery can play a big role in bringing this mission to fruition.

Public Health Spending

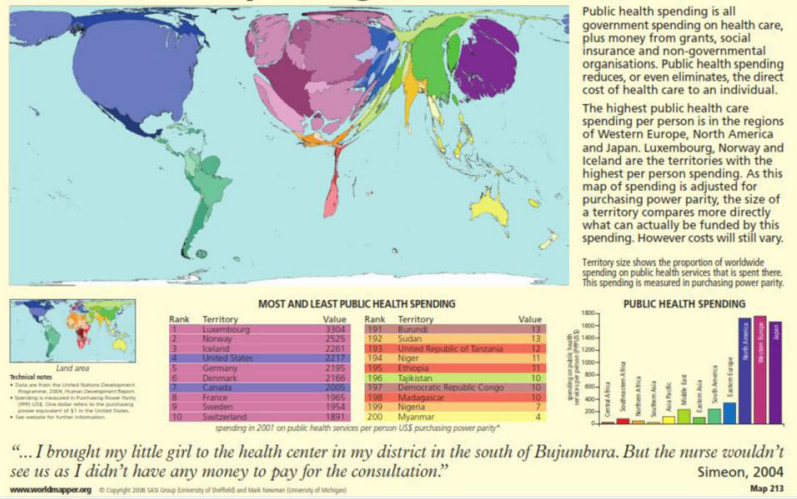

a

\section{Health Service Quality}

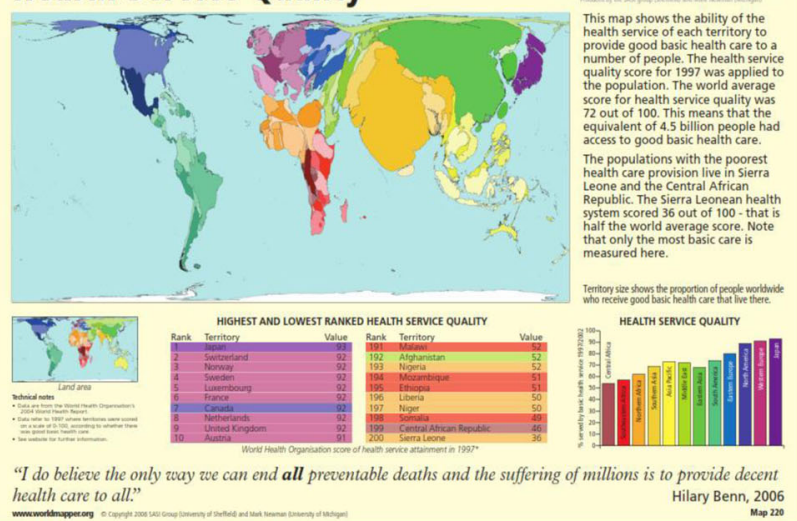

b

\section{Total Children}

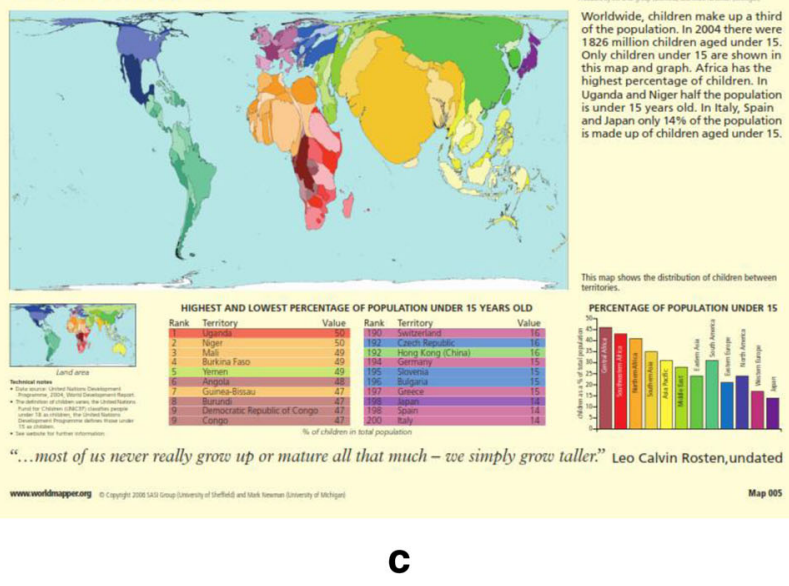

Fig. 7 Public health spending

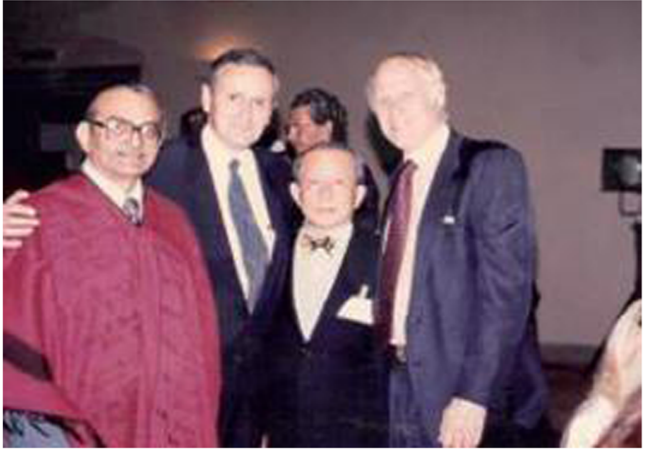

Fig. 8 Dr. Bhagwati as President of International Society of Pediatric Neurosurgery 1995

I would like to thank all our members and extend my support and best wishes to the incoming President, Graciella Zuccaro, who will take our organization to further heights.

\section{Postscript}

Recently, there has been a publication in Nature (May 2016) which may force a global rethink on the timeline of the cradle of civilization. This suggests that the Indus Valley Civilization is over 8000 years old and was preceded by a pre-Harappan phase of 1000 years. New findings in Bhirrana and Rakhigarhi in Haryana (north west India) have shown fully built structures like Harappa and it seems that this civilization died with dwindling monsoon in 7000 B.C. and change in cropping pattern led to a gradual breakdown of the urban settlement. The excavation trenches near another site in south India, near Madurai, have also shown similar evidence of the preHarappan civilization, in the form of a mound with urban settlement which also probably ended because of unfavorable climate change [12].

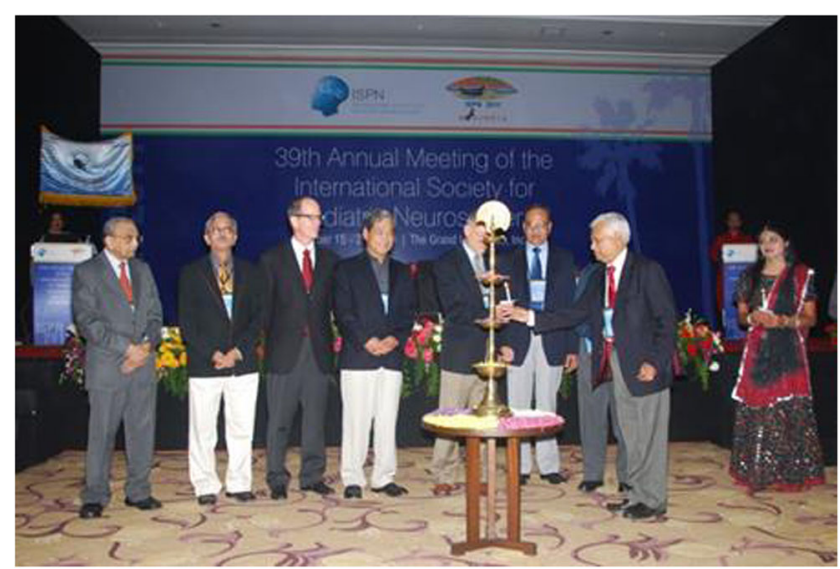

Fig. 9 Inaugural function of ISPN 2011, Goa by the Indian traditional lamp lighting ceremony 
Acknowledgments I would like to thank my daughter Aditi for helping me write this article and my secretary Maria Rodrigues and Associate Dr. Vikram Karmarkar for assistance with proofs, pictures, etc.

\section{Compliance with ethical standards}

Conflict of interest I have no disclosure in terms of conflict of interest with the information provided or the sources.

\section{References}

1. Sidharth B.G. (1999) The celestial key to the Vedas - discovering the origins of the world's oldest civilization. Inner Traditions

2. Marshall John (ed) (1931) Mohenjo-Daro and the Indus Civilization

3. Roberto C (1999) Ka. Translated by Tim Parks. Vintage publications, London
4. Jawaharlal N (1946) The discovery of India. Oxford University Press, Delhi

5. Tharoor S. (2009) Why nations should pursue soft power. TED India

6. Naresh Khatri, Abhoy Ojha, Pawan Budhwar, Vasanthi Srinivasan, Arup Varma (2012) Management research in India: current state and future directions. IIMB Manag Rev 24:104-115

7. Loukas M, Lanteri A, Julie F, Shane Tubbs R, Maharaja G, Shoja MM, Yadav A, Rao VC (2010) Anatomy in ancient India: a focus on the Susruta Samhita. J Anat 217:646-650

8. Bhagwati S.N. (1996) Presidential Oration-ISPN

9. Wong J, Panchmatia J, Ziewacz J, Bader A, Dunn I, Laws E, Gawande A (2012) Patterns in neurosurgical events: intracranial neoplasm surgery. Neurosurg Focus 33(5):E16

10. LCouldwell WT, Rovit R (2002) Rethinking neurosurgical subspecialization. Surg Neurol 58(6):359-363 discussion 363-70

11. Muzumdar D (2008) Editorial—advanced subspecialization in medical subspecialty practice in India: are we ready for it? J Postgrad Med 54(4)

12. Nature.com June 2, 2016 